\title{
Satisfaction with dental care among patients who receive invasive or non- invasive treatment for non-cavitated early dental caries: findings from one region of the National Dental PBRN
}

Sonya T. Mitchell ${ }^{1 *}$, Ellen Funkhouser², Valeria V. Gordan ${ }^{3}$, Joseph L. Riley $\|^{3}{ }^{3}$, Sonia K. Makhija ${ }^{1}$, Mark S. Litaker ${ }^{1}$, Gregg H. Gilbert ${ }^{1}$ and National Dental PBRN Collaborative Group

\begin{abstract}
Background: The objectives were to: (1) quantify patient satisfaction with treatment for early dental caries overall, and according to whether or not (2a) the patient received invasive treatment; (2b) was high-risk for dental caries, and had dental insurance; and (3) encourage practitioners to begin using non-invasive approaches to early caries management.

Methods: Ten practitioners recorded patient, lesion, and treatment information about non-cavitated early caries lesions. Information on 276 consecutive patients with complete data was included, who received either non-invasive (no dental restoration) or invasive (dental restoration) treatment. Patients completed a patient satisfaction questionnaire and were classified as dissatisfied if they did not "agree" or "strongly agree" with any of 14 satisfaction items.

Results: Patients had a mean ( \pm SD) age of $41.8( \pm 15.8)$ years, $64 \%$ were female and $88 \%$ were white. Twenty-five percent $(n=68)$ were dissatisfied in at least one of the 14 satisfaction items. Satisfaction levels did not significantly vary by patient's gender, race, caries risk category, or affected tooth surface location. Overall, $11 \%$ (28 of 276) received invasive treatment; satisfaction did not differ between patients who had invasive or non-invasive treatment. Seven patients received invasive treatment at their request even though that was not what their practitioner recommended; 5 out of 6 were satisfied with their treatment nonetheless.
\end{abstract}

Conclusions: About one-fourth of patients treated for non-cavitated early caries were dissatisfied with at least some aspect of their dental care experience. Satisfaction of patients who received invasive treatment did not differ from those who received non-invasive treatment.

Keywords: Patient satisfaction, Practice-based research, Dentistry, Non-invasive treatment, Invasive treatment

\footnotetext{
* Correspondence: mit@uab.edu

${ }^{1}$ University of Alabama at Birmingham, SDB Room 609; Box 48, 1720 Second

Avenue South, Birmingham, AL 35294-0007, USA

Full list of author information is available at the end of the article
} 


\section{Background}

Patient satisfaction can impact a patient's likelihood of choosing a dentist, arranging and keeping appointments, and complying with dentists' instructions [1-8]. Therefore, patient satisfaction is a salient component of health care and one that has the potential to impact treatment outcomes. Literature supports the notion that a healthy dentist-patient relationship contributes to higher patient satisfaction, and a recent review concluded that patients were more positive about a dental practice when they felt that the dental team listened to their concerns [9]. Research has shown that patient education and decision aids can improve the provider-patient relationship and improve decision-related outcomes [9, 10]. Therefore, the current study developed patient education materials specific to early caries management, provided them to participating dentists, and advised them regarding their use with patients.

Levels of satisfaction may differ by dental procedure and by which clinical populations are being served. Unfortunately, most studies have focused on dental visits in general $[11,12]$ and have sampled from the community without regard to time lag or the type of dental care received [3, 13-15]. Additionally, many studies have taken place in university dental clinics, a setting for which generalizability to other practice settings may be debatable $[2,16-18]$. Consequently, with the exception of prosthetic $[19,20]$ and orthodontic [21] procedures, there is little information about dental patient satisfaction with specific types of dental procedures. The placement of dental restorations is one of the most commonly performed procedures by general dentists [22, 23], yet little is known about patient satisfaction with visits having to do with caries management and dental restorations [5, 12, 24].

There is substantial variation in caries diagnosis and management $[25,26]$, with many dentists choosing an invasive approach (i.e., a dental restoration) rather than non-invasive treatment methods (e.g., "watchful monitoring" combined with prevention) for early caries. More recent published literature supports the benefits of minimally invasive dentistry. For example, an FDI World Dental Federation policy statement on managing dental caries supports minimally invasive operative interventions [27, 28]. Also, the American Academy of Pediatric Dentistry's published Guideline on Restorative Dentistry recommends active surveillance of non-cavitated carious lesions with preventive management [29]. Nonetheless, third party payers reimburse surgical procedures at a higher rate than the surveillance procedures that are consistent with evidence-based dentistry policy statements. The decision to place the first restoration on a tooth surface is an important one because it often is the beginning of an unfortunate cycle of restoration replacement over subsequent decades in which each succeeding restoration is progressively larger, ultimately leading to a large restoration [30-32] that places the tooth at increased risk for extraction [33, 34]. Approaches that delay placement of the first restoration may be a key source of improving the long-term effectiveness of dental care and therefore its quality [33, 35].

The National Dental Practice-Based Research Network (National Dental PBRN) is a consortium of dental practices and dental organizations focused on improving the scientific basis for clinical decision-making [36, 37]. This project initiated a line of research that was ultimately aimed at improving the quality of care in dental practices by introducing evidence-based decision-making information into routine practice. This project aimed to capitalize on information collected in two previous network studies of early caries diagnosis and treatment $[25,26,38]$ and generate basic information for future studies that would be designed to decrease variation in caries treatment. Beginning as a small-scale study limited to one network region, 10 Alabama practitioners were identified who would intervene invasively (i.e., do a dental restoration) on a non-cavitated caries lesion that was only into the enamel. These practitioners received in-office education about non-invasive treatment options and the latest scientific evidence about them.

For the purposes of the current study, early caries is defined as non-cavitated lesions confined to the enamel. Furthermore, non-invasive treatment is defined as watchful monitoring combined with prevention: oral hygiene instructions, diet counseling, fluoride treatments (rinse, gel, or paste), antibacterial rinses, varnishes or sealants. Air abrasion prior to sealing an early carious lesion was considered non-invasive as well.

The objectives for this study were to: (1) quantify patient satisfaction with treatment for early dental caries overall, and according to whether or not (2a) the patient received invasive treatment; (2b) was high-risk for dental caries, and had dental insurance; and (3) encourage practitioners to begin using non-invasive approaches to early caries management.

\section{Methods \\ Multi-phased approach}

The long-range goal of this line of research was to improve the quality of dental care by fostering movement of the latest scientific advances into routine clinical practice, specifically in the area of treatment of non-cavitated early caries. This plan involved four phases as illustrated in Fig. 1. Beginning as a small-scale study limited to one network region, the plan commenced after 10 Alabama practitioners were identified who had reported during a questionnaire study about caries diagnosis and caries treatment $[26,38]$ that they would intervene invasively (i.e., do a dental restoration) on a non-cavitated caries 


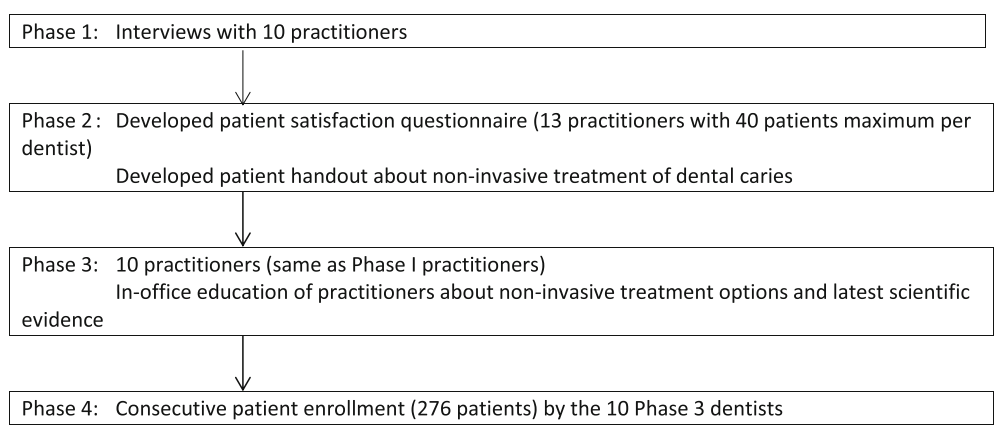

Fig. 1 Flow chart describing the multi-phased approach to this study

lesion that was only into the enamel. In a subsequent clinical study of dental restorations done on previouslyunrestored tooth surfaces [25], we confirmed that these same 10 practitioners did indeed restore some noncavitated lesions that were only into the enamel.

Phase 1 involved semi-structured interviews with these 10 practitioners. During the interviews, these practitioners expressed several barriers to providing noninvasive treatment. These were: (1) patients need help understanding why non-invasive treatment is advantageous; (2) some practitioners fear that if non-invasive treatment leads to an outcome that patients perceive as very negative (e.g., advanced caries), then the patient (or another local dentist from whom the patient decides to begin receiving treatment) will harbor negative attitudes toward the practitioner; (3) practitioners did not want to be seen as outliers, and therefore would like to be able to provide a brochure to help legitimize and validate the non-invasive treatment approach. These Phase 1 results informed the activities that occurred in Phase 2.

Phase 2 entailed developing a patient satisfaction questionnaire specific to early caries management; developing a patient handout about non-invasive treatment of dental caries; and obtaining input from dentists and patients about how best to use the handout to educate patients about non-invasive treatment. Phase 2 obtained input from these 10 practitioners and 30 of their patients during the development of the handout and its feasibility testing, as well as from 10 patients and 3 dentists in the University of Alabama at Birmingham faculty practice.

Phase 3 involved in-office education of the practitioners about non-invasive treatment options and the latest scientific evidence about them. The educational materials used in Phase 3 are publicly available at the network's web site [39]. One objective of this phase was to encourage these 10 practitioners to begin using noninvasive approaches to early caries management.

Phase 4 involved demonstrating to dentists - by engaging consecutive patients who have non-cavitated dental caries from their own practices during actual clinical encounters - that patient satisfaction was comparable or higher among patients who received non-invasive treatment as compared to invasive treatment. The data collection forms (Consecutive Patient Log; Caries Risk Assessment Form; Patient and Clinical Characteristics Data Collection Form; Patient Satisfaction Survey) used during this phase are publicly available at the network's web site [39].

\section{Phase 4 study procedures}

Practitioners explained the study to eligible consecutive patients during the data collection period. To be eligible, a patient had to have at least one non-cavitated early caries lesion, defined as confined to the enamel based on the practitioner's assessment of the clinical and/or radiographic appearance. Additionally, the patient had to be 19 years old or older and had to receive treatment for this lesion (either invasive or non-invasive treatment) during the current appointment or at the next appointment. If the patient provided informed consent, he or she was enrolled in the study, given the patient education brochure, and asked to read the brochure. The practitioner then explained or reviewed the content of the brochure with the patient. The practitioner next completed a Caries Risk Assessment Form about the patient's caries status.

The practitioner next recorded information about patient characteristics (e.g., the patient's gender, age, race, presence or absence of dental insurance, caries risk, and number of early caries lesions). Practitioners also recorded tooth-level characteristics (which surfaces had non-cavitated enamel caries; depth of the lesion), as well as what treatment was selected (monitoring; oral hygiene instruction; applying/ prescribing fluoride; applying varnish; sealant placement; enameloplasty; preventive resin restoration; full restoration; other). "Preventive resin restoration" and "full restoration" were classified as invasive treatment; all other options were classified as non-invasive treatment. Patients were informed about monitoring lesions and instructions were documented in the patient's treatment record. Patients received an explanation of the advantages and prognosis of caries preventive programs. If the practitioner recommended a non-invasive treatment to the patient, but the patient requested an invasive treatment anyway, the 
practitioner recorded the reason (does not have time for home care; does not believe that non-invasive treatment works; prefers a quick-fix to the problem; other). After the patient treatment was completed, the patient was given a Patient Satisfaction Survey Questionnaire (Appendix) and asked to mail that to the project's research assistant at the University of Alabama at Birmingham. All treatment options offered to the patient were considered standard of care; yet, the patients selected their preferred treatment after receiving an explanation of advantages and prognosis from the treating dentist. No effort was made to assign or prescribe treatment because we wanted to evaluate dentistry as it is actually provided by practitioners in a private practice, "real-world" setting. This is a key distinction between efficacy research (outcome observed as a result of ideal treatment) and effectiveness research (outcome observed as a result of treatment as provided in real-world settings).

\section{Statistical methods}

Satisfaction was assessed separately for each of the 14 questions, as well as for the proportion of the 14 questions with which the patient agreed or strongly agreed and whether or not satisfied on all 14 questions. Satisfaction levels were compared across the 10 practitioners, as were proportion of patients who were high-risk and proportion who had a lesion restored. Analyses were performed at the practitioner level using the Wilcoxon rank-sum test to assess statistical significance of findings. As the objective of this phase was to demonstrate the comparability of satisfaction levels for patients receiving non-invasive and invasive treatment, with the number of practitioners already determined, it was designed to be descriptive, not for hypothesis testing. Analyses were conducted using SAS software (SAS v9.4, SAS Institute Inc., Cary NC).

\section{Results}

Each of the 10 practitioners enrolled a maximum of 40 patients (actual range of 17 to 38), for a total of 295 patients enrolled. Restorative data forms were available for 289 patients; 287 patients completed a post-treatment survey - 277 had all 3 forms, but 1 patient survey was missing 13 of 14 questions on satisfaction; analysis is based on 276 patients.

All 10 practitioners were male, general dentists, and owned their dental practice. They had a mean $( \pm$ SD) years since received dental degree of $23.6( \pm 6.7)$, range: $10-32$, and mean number of patient visits per week was $42.2( \pm 22.4)$, range: $20-90$.

Characteristics of the patients, lesions, and treatment are presented in Table 1 . The mean $( \pm$ SD) age was 41.8 $( \pm 15.8)$ years; range 19 to 84 years. Approximately $64 \%$ were female, $88 \%$ were White, and $79 \%$ had at least some dental insurance or third party coverage. Most
(71\%) patients had moderate caries risk; $54 \%$ had only one early caries lesion. A total of 492 lesions were enrolled. The tooth surface that was most commonly affected with early caries was the occlusal surface comprising $70 \%(n=302)$ of the early caries lesions in the study. Of the lesions on occlusal surfaces, $14 \%(n=$ 42, 5 missing depth) were in the inner one-half of the enamel. As shown in Table 1, monitoring and oral hygiene instructions were by far the most commonly recommended treatment, each recommended for $99 \%$ of the early caries lesions. Only 57 (13\%) lesions were recommended for a restoration (either a full restoration or a preventive resin restoration). Among 244 patients for whom no restoration was recommended, seven patients (total of 13 lesions) chose a restorative treatment anyway. Among these seven patients, three preferred a quick fix to the problem, one did not believe that non-invasive treatment is effective, and four did not provide a reason.

As illustrated in Table 2, the percent satisfied on each of the 14 indices ranged from 84 to $99 \%$. Also, Table 3 depicts the mean proportion satisfied was $96 \%$. Overall, $208(75 \%)$ were satisfied with all items; 68 (25\%) were dissatisfied in at least one of the 14 satisfaction items, of which 35 (51\%) included the aspect of cost, and 2 were not satisfied with any of the 14 items.

One practitioner had notably lower satisfaction scores than the other nine practitioners as shown in Table 2; $35 \%$ versus $80 \%$ patients were satisfied on all 14 items, and in Table 3, mean proportions satisfied were $80 \%$ versus $97 \%$. Lower satisfaction scores for this practitioner were observed on all questions except cost; this score was comparable to that of other practitioners. As evident in Table 3, this practitioner did not appear to have a different patient population in terms of proportion that were high-risk ( $12 \%$ versus $17 \%)$ or for whom a lesion was restored ( $15 \%$ versus $11 \%)$. The proportion of patients with dental insurance was lower for this practitioner (73\% versus $80 \%)$.

Neither overall patient satisfaction, nor satisfaction related to costs, differed for patients who received invasive compared to non-invasive treatment; the mean proportion satisfied was $96 \%$ for both groups. Adjusting for dental insurance did not affect this, namely, presence of dental insurance was not significantly associated with satisfaction or receiving invasive treatment.

\section{Discussion}

This was a small-scale study in which ten practitioners in one network region recorded patient, lesion, and treatment information about non-cavitated early caries lesions. These practitioners had reported during a questionnaire study about caries diagnosis and caries treatment [26, 38] that they would intervene invasively (i.e., do a dental restoration) on a non-cavitated caries lesion that was only 
Table 1 Characteristics of enrolled patients $(n=276)$, caries lesions $(n=429)$, and treatment

\begin{tabular}{|c|c|c|}
\hline & $\mathrm{n}$ & $\%$ \\
\hline \multicolumn{3}{|l|}{ Patient characteristics } \\
\hline \multicolumn{3}{|l|}{ Patient's gender } \\
\hline Male & 99 & 36 \\
\hline Female & 176 & 64 \\
\hline missing & 1 & \\
\hline \multicolumn{3}{|l|}{ Patient's race } \\
\hline White & 242 & 88 \\
\hline Black/African-American & 24 & 9 \\
\hline Asian & 3 & 1 \\
\hline Other & 4 & 2 \\
\hline missing & 3 & \\
\hline \multicolumn{3}{|l|}{ Patient's age group } \\
\hline 19-24 years old & 32 & 12 \\
\hline 25-39 years old & 103 & 38 \\
\hline 40-54 years old & 81 & 30 \\
\hline 55 years old or older & 57 & 21 \\
\hline missing & 3 & \\
\hline \multicolumn{3}{|c|}{ Patient has any dental insurance } \\
\hline Yes & 218 & 79 \\
\hline No & 58 & 21 \\
\hline \multicolumn{3}{|c|}{ Patient's caries risk as determined by the practitioner ${ }^{a}$} \\
\hline Low risk & 35 & 13 \\
\hline Moderate risk & 195 & 71 \\
\hline High risk & 46 & 17 \\
\hline
\end{tabular}

Number of early caries lesions in patient as determined by the practitioner

$\begin{array}{lll}1 & 150 & 54 \\ 2 & 63 & 23 \\ 3 & 36 & 13 \\ 4 & 27 & 10\end{array}$

Caries lesion characteristics

Tooth surfaces with early caries

$\begin{array}{lll}\text { Occlusal } & 302 & 70 \\ \text { Mesial } & 57 & 13 \\ \text { Distal } & 62 & 15 \\ \text { Buccal or Facial } & 107 & 25 \\ \text { Lingual or Palatal } & 34 & 8 \\ \text { Incisal } & 9 & 2 \\ \text { missing } & 4 & \end{array}$

Practitioner's preoperative assessment of the deepest part of the early caries lesion

$\begin{array}{lll}\text { In the outer one-half of the enamel } & 345 & 81 \\ \text { In the inner one-half of the enamel } & 79 & 19 \\ \text { missing } & 5 & \end{array}$

Table 1 Characteristics of enrolled patients $(n=276)$, caries lesions ( $n=429)$, and treatment (Continued)

\begin{tabular}{lll}
\hline Treatment recommended to patient for these lesions & \\
Monitoring & 424 & 99 \\
Oral hygiene instruction & 426 & 99 \\
Applying or prescribing fluoride & 98 & 23 \\
Applying varnish & 9 & 2 \\
Sealant placement & 6 & 1 \\
Enameloplasty & 0 & 0 \\
Preventive resin restoration & 17 & 4 \\
Full restoration & 40 & 9
\end{tabular}

asing the American Dental Association Caries Risk Assessment Form (available at the citation for this manuscript at the network's web site at http://nationaldentalpbrn.org/tyfoon/site/fckeditor/

Caries\%20Risk\%20Assessment\%20Form.pdf). A score of 0 indicates that the patient is low-risk. A score of 1-9 means moderate risk. A score of 10 or more indicates high-risk

${ }^{\mathrm{b}}$ Multiple choices were possible

into the enamel. In this study, we quantified patient satisfaction with dental care immediately following therapeutic care for early dental caries. Although results from Phase 4 of this line of research are the focus of this report, findings from the first three phases were also elucidative. Because the only practitioners who participated were those who had previously reported doing invasive treatment for enamel caries, which was subsequently verified during a clinical study, the Phase 1 results were revealing in that these practitioners cited three key barriers to using non-invasive treatment in their practices. These were: (1) patients need help understanding why non-invasive treatment is advantageous; (2) some practitioners fear that if non-invasive treatment leads to an outcome that patients perceive as very negative (e.g., advanced caries), then the patient (or another local dentist from whom the patient decides to begin receiving treatment) will harbor negative attitudes toward the practitioner; (3) practitioners did not want to be seen as outliers, and therefore would like to be able to provide a brochure to help legitimize and validate the non-invasive treatment approach. Additionally, the Phase 1 results guided the design of the informational materials used during the Phase 2 and 3 interventions, making use of the circumstance that these practitioners represented the characteristics of the main target group for the intervention ultimately envisioned after the Phase 4 study had been completed. Another finding was that patient satisfaction levels were the same for patients receiving invasive and those receiving non-invasive therapy. An additional finding was that some patients declined the dentist's noninvasive treatment suggestion, desiring a surgical treatment approach instead, constituting an informed refusal. While a dentist may believe a surgical approach is not in the patient's best interest, patient consent is still required prior to the delivery of dental care. However, a dentist 
Table 2 Percent of patients who indicated satisfaction by questionnaire item, overall and separately for each practitioner

\begin{tabular}{|c|c|c|c|c|c|c|c|c|c|}
\hline \multirow[b]{2}{*}{ Questionnaire item } & \multicolumn{3}{|c|}{$\begin{array}{l}\text { ALL } 10 \text { Practitioners } \\
(N=276 \text { patients) }\end{array}$} & \multicolumn{3}{|c|}{$\begin{array}{l}9 \text { Practitioners } \\
(N=250 \text { patients) }\end{array}$} & \multicolumn{3}{|c|}{$\begin{array}{l}\text { Practitioner with low } \\
\text { satisfaction scores } \\
\text { ( } N=26 \text { patients) }\end{array}$} \\
\hline & $\begin{array}{l}\text { \# satisfied } \\
\text { patients (n) }\end{array}$ & $\begin{array}{l}\% \\
\text { satisfied }\end{array}$ & $\begin{array}{l}\# \\
\text { missing }\end{array}$ & $\begin{array}{l}\text { \# satisfied } \\
\text { patients (n) }\end{array}$ & $\begin{array}{l}\% \\
\text { satisfied }\end{array}$ & $\begin{array}{l}\# \\
\text { missing }\end{array}$ & $\begin{array}{l}\text { \# satisfied } \\
\text { patients (n) }\end{array}$ & $\begin{array}{l}\% \\
\text { satisfied }\end{array}$ & $\begin{array}{l}\# \\
\text { missing }\end{array}$ \\
\hline \multicolumn{10}{|l|}{ I am satisfied .... } \\
\hline $\begin{array}{l}\text {.... that I was able to ask questions about my } \\
\text { dental treatment }\end{array}$ & 272 & 99 & 0 & 248 & 99 & 0 & 24 & 92 & 0 \\
\hline .... that my dentist respects me as a person & 271 & 99 & 1 & 247 & 99 & 0 & 24 & 96 & 1 \\
\hline .... with the skill of my dentist & 268 & 98 & 2 & 247 & 99 & 1 & 21 & 84 & 1 \\
\hline .... with how thorough my dentist was & 267 & 97 & 1 & 246 & 99 & 1 & 21 & 81 & 0 \\
\hline .... with the friendliness of my dentist & 266 & 97 & 2 & 244 & 98 & 2 & 22 & 85 & 0 \\
\hline $\begin{array}{l}\text {.... with the amount of trust that I can place in } \\
\text { my dentist }\end{array}$ & 265 & 96 & 1 & 245 & 98 & 1 & 20 & 77 & 0 \\
\hline $\begin{array}{l}\text {.... was free to make decisions about my dental } \\
\text { problems }\end{array}$ & 265 & 96 & 0 & 244 & 98 & 0 & 18 & 69 & 0 \\
\hline .... with the treatment I received & 260 & 96 & 5 & 238 & 97 & 5 & 22 & 85 & 0 \\
\hline $\begin{array}{l}\text {.... with how dentist presented options for } \\
\text { treatment }\end{array}$ & 264 & 96 & 0 & 245 & 98 & 0 & 19 & 73 & 0 \\
\hline $\begin{array}{l}\text {.... with the treatment information and handouts } \\
\text { provided }\end{array}$ & 264 & 96 & 0 & 244 & 98 & 0 & 20 & 77 & 0 \\
\hline .... with the amount of information I received & 264 & 96 & 0 & 246 & 98 & 0 & 18 & 69 & 0 \\
\hline .... that my dentist understood my concerns & 263 & 95 & 0 & 244 & 98 & 0 & 19 & 73 & 0 \\
\hline $\begin{array}{l}\text {.... with the quality of tooth decay treatment } \\
\text { received }\end{array}$ & 262 & 95 & 0 & 245 & 98 & 0 & 17 & 65 & 0 \\
\hline .... with the cost of my treatment & 241 & 84 & 0 & 218 & 87 & 0 & 23 & 89 & 0 \\
\hline Satisfied with ALL & 208 & 75 & 0 & 199 & 80 & 0 & 9 & 35 & 0 \\
\hline
\end{tabular}

Responses were classified as "satisfied" if patients responded that they "Agree" or "Strongly Agree" with the statement Denominator is column heading $(276,250$, or 26$)$ minus missing

Table 3 Summary characteristics by practitioner

\begin{tabular}{|c|c|c|c|c|c|c|c|c|c|c|c|}
\hline \multirow[b]{2}{*}{ Dentist } & \multirow[b]{2}{*}{ \# patients } & \multicolumn{2}{|c|}{$\begin{array}{l}\text { Satisfied on } \\
\text { all } 14 \text { questions }\end{array}$} & \multicolumn{2}{|c|}{$\begin{array}{l}\text { proportion } \\
\text { satisfied }\end{array}$} & \multicolumn{2}{|c|}{$\begin{array}{l}\text { \# of high-risk } \\
\text { patients }\end{array}$} & \multicolumn{2}{|c|}{$\begin{array}{l}\text { \# patients had } \\
\text { a lesion restored }\end{array}$} & \multicolumn{2}{|c|}{$\begin{array}{l}\text { \# patients had } \\
\text { dental insurance }\end{array}$} \\
\hline & & $\mathrm{N}$ & $\%$ & mean & SD & $\mathrm{N}$ & $\%$ & $\mathrm{~N}$ & $\%$ & $\mathrm{~N}$ & $\%$ \\
\hline A & 26 & 9 & $35 \%$ & 80 & 21 & 3 & $12 \%$ & 4 & $15 \%$ & 19 & $73 \%$ \\
\hline B & 17 & 11 & $65 \%$ & 98 & 4 & 6 & $35 \%$ & 10 & $59 \%$ & 14 & $82 \%$ \\
\hline C & 25 & 17 & $68 \%$ & 97 & 5 & 4 & $16 \%$ & 0 & $0 \%$ & 15 & $60 \%$ \\
\hline D & 28 & 21 & $75 \%$ & 98 & 5 & 11 & $39 \%$ & 7 & $25 \%$ & 23 & $82 \%$ \\
\hline$E$ & 38 & 30 & $79 \%$ & 96 & 16 & 0 & $0 \%$ & 0 & $0 \%$ & 24 & $63 \%$ \\
\hline$F$ & 29 & 23 & $79 \%$ & 98 & 4 & 1 & $3 \%$ & 1 & $3 \%$ & 22 & $76 \%$ \\
\hline G & 27 & 22 & $81 \%$ & 95 & 19 & 15 & $56 \%$ & 1 & $4 \%$ & 23 & $85 \%$ \\
\hline $\mathrm{H}$ & 37 & 32 & $86 \%$ & 97 & 12 & 3 & $8 \%$ & 1 & $3 \%$ & 37 & $100 \%$ \\
\hline | & 24 & 21 & $88 \%$ & 99 & 3 & 7 & $29 \%$ & 0 & $0 \%$ & 19 & $79 \%$ \\
\hline J & 25 & 22 & $88 \%$ & 99 & 3 & 6 & $24 \%$ & 8 & $32 \%$ & 22 & $88 \%$ \\
\hline overall & 276 & 208 & $75 \%$ & 96 & 13 & 46 & $17 \%$ & 32 & $12 \%$ & 218 & $76 \%$ \\
\hline All except A & 250 & 199 & $80 \%$ & 97 & 10 & 43 & $17 \%$ & 28 & $11 \%$ & 199 & $80 \%$ \\
\hline A & 26 & 9 & $35 \%$ & 80 & 21 & 3 & $12 \%$ & 4 & $15 \%$ & 19 & $73 \%$ \\
\hline $\mathrm{p}^{*}=$ & & 0.2 & & 0.2 & & 0.9 & & 0.6 & & 0.4 & \\
\hline
\end{tabular}

*Wilcoxon rank sum, 2-tailed for Dentist A compared to all others 
knowingly performing invasive treatment when current evidence-based literature supports minimally invasive dentistry raises ethical considerations. The ethical balance between patient autonomy and the practice of evidencebased dentistry can be challenging with these emerging philosophies of care, and the need to consider this balance did not become evident until these patients refused noninvasive treatment during this study. Regardless of treatment type, the lowest satisfaction rating was the item based on patient satisfaction with the cost of treatment (84\% satisfaction). The practitioners did not cite costs of non-invasive dental procedures or a lack of dental insurance coverage for non-invasive treatment as barriers to non-invasive therapy in their practices; however, this study found the greatest factor of patient dissatisfaction to be cost. Patient rationale for dissatisfaction with invasive and non-invasive treatment cost is an area worthy of further exploration.

\section{Factors associated with patient satisfaction}

Numerous studies in medicine have focused on patients' perceptions, and demonstrated that there is a discrepancy between medical professionals' and patients' perceptions about the treatment they receive $[4,40,41]$. Patient satisfaction is important because of its link to regular return visits, caregiver trust, perception of technical competence, and treatment outcomes. The dentistpatient relationship has been found to be the most important aspect of patient satisfaction [2]. It is curious that one practitioner in Table 3, practitioner ' $\mathrm{A}$ ', had substantively lower overall satisfaction ratings than the other practitioners. One possible explanation is that he or she felt more uncomfortable in recommending noninvasive therapy, although no measures of this discomfort were included in this study. Several studies have shown that patients evaluate the quality of their dental care based on a range of criteria, particularly their dentist's interpersonal communication [2, 3, 5, 11, 42-46]. A positive correlation has been found between the dental team's ability to communicate effectively and patient satisfaction [1-3, 42, 44, 45, 47, 48]. Therefore, a component of the patient satisfaction questionnaire in this study consisted of items enquiring about the patient's immediate experiences during their dental visit. This includes the perceived interpersonal relationship between patient and dentist that may represent the patient's view of the skills of the dentist (e.g., a skillful dentist is a painless dentist).

In this study, patient satisfaction was recorded immediately after treatment and patients were not followed longitudinally. About one-fourth of consecutive patients treated for early caries were dissatisfied with some aspect of their dental care experience. Interestingly, mean satisfaction levels of patients who received invasive treatment for early caries did not differ from those who received non-invasive treatment for early caries. This may be due to other factors that lead to patient satisfaction than whether a dentist utilizes a surgical or nonsurgical approach to dental treatment.

All fourteen satisfaction questions in this study received high patient satisfaction ratings. Twelve of the fourteen satisfaction questions received an average satisfaction score of $>90 \%$. Two of the fourteen questions received satisfaction endorsement by more than $80 \%$ of patients. This study suggests that either the patients were satisfied with the level of technical competence or that their professional needs were addressed satisfactorily; however, the patient's communication needs regarding cost were met to a lesser degree than technical competence, friendliness and trust.

This study quantified immediate satisfaction with dental care among patients who received treatment for early dental caries and tested the hypotheses that patients who receive non-invasive treatment have higher satisfaction levels than those who receive invasive treatment; and certain patient-level factors are associated with satisfaction. The measure of patient satisfaction was developed specifically for invasive versus non-invasive restorative procedures. Overall, the patient's satisfaction levels were high. An interesting finding in this study is the similarity in patient satisfaction between invasive and non-invasive dental therapy. This could be explained by the high level of trust a patient places on his/her dentist's treatment recommendations.

This project has laid important groundwork for designing an intervention to improve early caries treatment by enhancing the translation of research findings into routine clinical practice, making use of the unique advantages of a dental PBRN. The ultimate objective is better oral health at the population level. Achieving patient satisfaction is multifactorial and critical to patient compliance and thus improved oral healthcare. Communication is paramount in achieving patient satisfaction and may hold as much importance to a patient as the technical skill of the dental team. To our knowledge, there is no literature about patients' declination of noninvasive caries treatment, in favor of invasive treatment.

\section{Conclusions}

About one-fourth of patients treated for non-cavitated early caries were dissatisfied with at least some aspect of their dental care experience. Satisfaction of patients who received invasive treatment did not differ from those who received non-invasive treatment. A small percentage of patients declined the dentist's recommendation for non-invasive treatment and chose invasive dental treatment instead. 


\section{Appendix}

Table 4 Patient satisfaction survey questionnaire

\begin{tabular}{|c|c|c|c|c|c|}
\hline & $\begin{array}{l}\text { Strongly } \\
\text { disagree }\end{array}$ & Disagree & $\begin{array}{l}\text { Neither agree } \\
\text { nor disagree }\end{array}$ & Agree & $\begin{array}{l}\text { Strongly } \\
\text { agree }\end{array}$ \\
\hline $\begin{array}{l}\text { 1. I am satisfied with how my dentist presented all the options for the treatment } \\
\text { of my tooth decay. }\end{array}$ & 1 & 2 & 3 & 4 & 5 \\
\hline 2. I am satisfied with the quality of tooth decay treatment that I received. & 1 & 2 & 3 & 4 & 5 \\
\hline 3. I am satisfied with the amount of trust that I can place in my dentist. & 1 & 2 & 3 & 4 & 5 \\
\hline 4. I am satisfied with how thorough my dentist was. & 1 & 2 & 3 & 4 & 5 \\
\hline 5. I am satisfied with the treatment information and handouts provided. & 1 & 2 & 3 & 4 & 5 \\
\hline 6. I am satisfied that my dentist understood my concerns. & 1 & 2 & 3 & 4 & 5 \\
\hline $\begin{array}{l}\text { 7. I am satisfied with the amount of information about my dental treatment that I } \\
\text { received from my dentist. }\end{array}$ & 1 & 2 & 3 & 4 & 5 \\
\hline 8. I feel free to make decisions about my dental problems. & 1 & 2 & 3 & 4 & 5 \\
\hline 9. I am satisfied with the skill of my dentist. & 1 & 2 & 3 & 4 & 5 \\
\hline 10. I am satisfied that I was able to ask questions about my dental treatment. & 1 & 2 & 3 & 4 & 5 \\
\hline 11. I am satisfied with the cost of my treatment. & 1 & 2 & 3 & 4 & 5 \\
\hline 12. I am satisfied that my dentist respects me as a person. & 1 & 2 & 3 & 4 & 5 \\
\hline 13. I try to take my dentist's advice. & 1 & 2 & 3 & 4 & 5 \\
\hline 14. The dentist seemed to know what he was doing during my visit. & 1 & 2 & 3 & 4 & 5 \\
\hline 15. I will make changes to my lifestyle if they prevent getting a filling. & 1 & 2 & 3 & 4 & 5 \\
\hline 16. The dentist should make the important dental decisions, not me. & 1 & 2 & 3 & 4 & 5 \\
\hline 17. I am concerned about feeling pain when I go for dental care. & 1 & 2 & 3 & 4 & 5 \\
\hline 18. I am satisfied with the friendliness of my dentist. & 1 & 2 & 3 & 4 & 5 \\
\hline 19. Patients should know the cost of their treatment before the treatment begins. & 1 & 2 & 3 & 4 & 5 \\
\hline 20. I avoid going to the dentist because I dislike pain. & 1 & 2 & 3 & 4 & 5 \\
\hline 21. In general, the fees dentists charge are too high. & 1 & 2 & 3 & 4 & 5 \\
\hline $\begin{array}{l}\text { 22. I will choose the best treatment for my tooth decay, regardless of the } \\
\text { possibility of feeling pain. }\end{array}$ & 1 & 2 & 3 & 4 & 5 \\
\hline 23. Dentists should do more to reduce pain. & 1 & 2 & 3 & 4 & 5 \\
\hline 24. Dentists avoid unnecessary patient expenses. & 1 & 2 & 3 & 4 & 5 \\
\hline 25. My dentist tried to limit my fear and anxiety. & 1 & 2 & 3 & 4 & 5 \\
\hline 26. I will choose the best treatment for my tooth decay regardless of cost. & 1 & 2 & 3 & 4 & 5 \\
\hline 27. The dentist respected my opinion about my tooth decay treatment. & 1 & 2 & 3 & 4 & 5 \\
\hline 28. I will choose the same treatment for tooth decay on another tooth. & 1 & 2 & 3 & 4 & 5 \\
\hline 29. I am satisfied with the treatment I received. & 1 & 2 & 3 & 4 & 5 \\
\hline 30. I prefer a filling because it is a quick fix for my tooth decay. & 1 & 2 & 3 & 4 & 5 \\
\hline 31. I believe that a treatment to prevent a filling is better than getting a filling. & 1 & 2 & 3 & 4 & 5 \\
\hline
\end{tabular}

\section{Abbreviations}

FDI: Fédération Dentaire Internationale; n: Number; PBRN: Practice-based research network; SD: Standard deviation

\section{Acknowledgments}

Special acknowledgement is made of Dr. Andreea Voinea-Griffin, who collaborated with Drs. Gilbert, Gordan, Litaker, Makhija, and Riley on this project as a postdoctoral fellow and conducted the field work. An Internet site devoted to details about the nation's network is located at http://nationaldentalpbrn.org/faq.htm. Persons who comprise the National Dental PBRN Collaborative Group are listed at http://nationaldentalpbrn.org/collaborative- group.php. Opinions and assertions contained herein are those of the authors and are not to be construed as necessarily representing the views of the respective organizations or the National Institutes of Health. The authors report no financial conflicts of interest.

The National Dental PBRN Collaborative Group includes practitioner, faculty, and staff investigators who contributed to this activity.

\section{Funding}

This investigation was supported by NIH grants F32-DE-18952, U01-DE-16746, U01-DE-16747 and U19-DE-22516. 


\section{Availability of data and materials}

The data collection forms (Consecutive Patient Log; Caries Risk Assessment Form; Patient and Clinical Characteristics Data Collection Form; Patient Satisfaction Survey) used during phase 4 of the study are publicly available at the network's web site [http://nationaldentalpbrn.org/study-results/ development-of-a-patient-based-provider-intervention-for-early-cariesmanagement.php]. [39] The National Dental PBRN makes publicly available data from its studies after the grant's funding period has ended, in fully de-identified form.

\section{Authors' contributions}

All authors made substantial contributions to conception and design, or acquisition of data, or analysis and interpretation of data; were involved in drafting the manuscript; have given approval of this version of the manuscript; and agree to be accountable for all aspects of the work. STM was a major contributor in writing and editing the manuscript. EF analyzed and interpreted the patient data, and was a major contributor in writing the manuscript. WG analyzed and interpreted the patient data, and was a contributor in writing the manuscript. JLR made substantial contributions to conception and design, and was a contributor in writing the manuscript. SKM made substantial contributions to conception and design, and was a contributor in writing the manuscript. MSL analyzed and interpreted the patient data, and was a major contributor in writing the manuscript. GHG made substantial contributions to conception and design, and was a major contributor in writing the manuscript.

The National Dental PBRN Collaborative Group made substantial contributions to acquisition of data. All authors read and approved the final manuscript.

\section{Competing interests}

The authors declare that they have no competing interests.

\section{Consent for publication}

Not applicable.

\section{Ethics approval and consent to participate}

This study was reviewed and approved by the Institutional Review Board at the University of Alabama at Birmingham. Informed consent was obtained verbally from patients during phase 4 of this investigation following their review and discussion of a patient information sheet from the study. This was done because all treatment provided was considered standard of care. Practitioners provided written informed consent. This informed consent process was approved by the ethics committee.

\section{Publisher's Note}

Springer Nature remains neutral with regard to jurisdictional claims in published maps and institutional affiliations.

\section{Author details}

'University of Alabama at Birmingham, SDB Room 609; Box 48, 1720 Second Avenue South, Birmingham, AL 35294-0007, USA. ${ }^{2}$ Department of Preventive Medicine, School of Medicine, University of Alabama at Birmingham, Birmingham, AL, USA. ${ }^{3}$ Department of Restorative Dental Sciences, College of Dentistry, University of Florida, Gainesville, FL, USA.

Received: 17 August 2016 Accepted: 16 March 2017

Published online: 27 March 2017

\section{References}

1. Newsome PR, Wright GH. A review of patient satisfaction: 2. Dental patient satisfaction: an appraisal of recent literature. Br Dent J. 1999;186(4):166-70.

2. Gürdal P, Cankaya H, Onem E, Dinçer S, Yilmaz T. Factors of patient satisfaction/dissatisfaction in a dental faculty outpatient clinic in Turkey. Community Dent Oral Epidemiol. 2000;28(6):461-9.

3. Holt VP, McHugh K. Factors influencing patient loyalty to dentist and dental practice. Br Dent J. 1997;183(10):365-70.

4. Zimmermann RS. The dental appointment and patient behavior. Differences in patient and practitioner preferences, patient satisfaction, and adherence. Med Care. 1988;26(4):403-14.

5. Riley $\mathrm{L}$, Gordan W, Rindal DB, Fellows $\mathrm{L}$, Qvist V, Patel S, Foy P, Williams OD, Gilbert GH, Dental PBRN Collaborative Group. Components of patient satisfaction with a dental restorative visit: results from the Dental PBRN. J Am Dent Assoc. 2012;143(9):1002-10.

6. Ball R. Practical marketing for dentistry, part 3: relationship marketing and patient/customer satisfaction. Br Dent J. 1996;180(12):467-72.

7. Thomson WM, Stewart JF, Carter KD, Spencer AJ. Patient mobility in Australian dentistry. Community Dent Health. 1996;13(2):99-104.

8. Williams SJ, Calnan M. Convergence and divergence: assessing criteria of consumer satisfaction across general practice, dental and hospital care settings. Soc Sci Med. 1991;33(6):707-16.

9. Sbaraini A, Carter SM, Evans RW, Blinkhorn A. Experiences of dental care: what do patients value? BMC Health Serv Res. 2012;12:177. http://www. biomedcentral.com/content/pdf/1472-6963-12-177.pdf. Accessed 2 Feb 2016.

10. Lahti S, Tuutti H, Hausen H, Kääriäinen R. Comparison of ideal and actual behavior of patients and dentists during dental treatment. Community Dent Oral Epidemiol. 1995;23(6):374-8.

11. Calnan M, Dickinson M, Manley $G$. The quality of general dental care: public and users' perceptions. Qual Health Care. 1999;8(3):149-53.

12. Goedhart H, Eijkman MA, ter Horst G. Quality of dental care: the view of regular attenders. Community Dent Oral Epidemiol. 1996;24(1):28-31.

13. Gopalakrishna P, Munnaleneni V. Influencing satisfaction for dental services. J Health Care Mark. 1993;13(1):16-22.

14. Burke L, Croucher R. Criteria of good dental practice generated by general dental practitioners and patients. Int Dent J. 1996:46(1):3-9.

15. Riley $J$, Gordan W, Hudak-Boss SE, Fellows JL, Rindal DB, Gilbert GH, National Dental PBRN Collaborative Group. Concordance between patient satisfaction and the dentist's view; findings from The National Dental Practice-Based Research Network. J Am Dent Assoc. 2014;145(4):355-62.

16. Handelman SL, Jensen OE, Jensen P, Black PM. Patient satisfaction in a regular and after-hours dental clinic. Spec Care Dentist. 1996;16(5):194-8.

17. Chu CH, Yeung CY, Lo EC. Monitoring patient satisfaction with university dental services under two fee-paying systems. Community Dent Oral Epidemiol. 2001;29(5):390-8.

18. Alvesalo I, Uusi-Heikkilä Y. Use of services, care-seeking behavior and satisfaction among university dental clinic patients in Finland. Community Dent Oral Epidemiol. 1984;12(5):297-302.

19. Frank RP, Milgrom P, Leroux BG, Hawkins NR. Treatment outcomes with mandibular removable partial dentures: a population-based study of patient satisfaction. J Prosthet Dent. 1998;80(1):36-45.

20. Layton D, Walton T. Patient-evaluated dentistry: development and validation of a patient satisfaction questionnaire for fixed prosthodontic treatment. Int J Prosthodont. 2011;24(4):332-41.

21. Al-Omiri MK, Abu Alhaija ES. Factors affecting patient satisfaction after orthodontic treatment. Angle Orthod. 2006;76(3):422-31.

22. Mjör IA, Moorhead JE, Dahl JE. Reasons for replacement of restorations in permanent teeth in general dental practice. Int Dent J. 2000;50(6):361-6.

23. McDaniel RJ, Davis RD, Murchison DF, Cohen RB. Causes of failure among cuspal-coverage amalgam restorations: a clinical survey. J Am Dent Assoc. 2000;131(2):173-7.

24. Abrams RA, Ayers CS, Vogt Petterson M. Quality assessment of dental restorations: a comparison by dentists and patients. Community Dent Oral Epidemiol. 1986;14(6):317-9.

25. Nascimento MM, Gordan W, Qvist V, Litaker MS, Rindal DB, Williams OD, Fellows JL, Ritchie LK, Mjör IA, McClelland J, Gilbert GH, Dental PBRN Collaborative Group. Reasons for placement of restorations on previously unrestored tooth surfaces by dentists in The Dental Practice-Based Research Network. J Am Dent Assoc. 2010;141(4):441-8.

26. Gordan W, Bader JD, Garvan CW, Richman JS, Qvist V, Fellows JL, Rindal DB, Gilbert GH, Dental PBRN Collaborative Group. Restorative treatment thresholds for occlusal primary caries among dentists in The Dental Practice-Based Research Network. J Am Dent Assoc. 2010;141(2):171-84.

27. FDI Policy Statement: Minimal Intervention in the Management of Dental Caries. Adopted by the FDI General Assembly: 1 October 2002 - Vienna, Austria. http://www.fdiworlddental.org/resources/policy-statements-andresolutions. Assessed 10 Mar 2017.

28. Frencken JE, Peters MC, Manton DJ, Leal SC, Gordan W, Eden E. Minimal Intervention Dentistry (MID) for managing dental caries - a review: report of a FDI task group. Int Dent J. 2012;62(5):223-43. doi:10.1111/idj.12007.

29. Guideline on Restorative Dentistry. American Academy of Pediatric Dentistry. Reference Manual 2014;37(6):15-16. http://www.aapd.org/media/ policies_guidelines/g_restorative.pdf. Assessed 28 Sept 2016. 
30. Gordan W, Garvan CW, Blaser PK, Mondragon E, Mjör IA. A long-term evaluation of alternative treatments to replacement of resin-based composite restorations: results of a seven-year study. J Am Dent Assoc. 2009:140(12):1476-84.

31. Gordan W, Mondragon E, Shen C. Replacement of resin-based composite: evaluation of cavity design, cavity depth, and shade matching. Quintessence Int. 2002;33(4):273-8.

32. Gordan W. Clinical evaluation of replacement of class $V$ resin based composite restorations. J Dent. 2001;29(7):485-8.

33. Anusavice KJ. Present and future approaches for the control of caries. J Dent Educ. 2005;69(5):538-54.

34. Brantley CF, Bader JD, Shugars DA, Nesbit SP. Does the cycle of rerestoration lead to larger restorations? J Am Dent Assoc. 1995;126(10):1407-13.

35. Dennison JB, Hamilton JC. Treatment decisions and conservation of tooth structure. Dent Clin North Am. 2005;49(4):825-45.

36. Gilbert GH, Williams OD, Korelitz JJ, Fellows JL, Gordan W, Makhija SK, Meyerowitz C, Oates TW, Rindal DB, Benjamin PL, Foy PJ, National Dental PBRN Collaborative Group. Purpose, structure, and function of the United States National Dental Practice-Based Research Network. J Dent. 2013:41(11):1051-9.

37. Gilbert GH, Williams OD, Rindal DB, Pihlstrom DJ, Benjamin PL, Wallace MA, Dental PBRN Collaborative Group. The creation and development of The Dental Practice-Based Research Network. J Am Dent Assoc. 2008;139(1):74-81.

38. Gordan W, Garvan CW, Heft MW, Fellows JL, Qvist V, Rindal DB, Gilbert GH, Dental PBRN Collaborative Group. Restorative treatment thresholds for interproximal primary caries based on radiographic images: findings from The Dental Practice-Based Research Network. Gen Dent. 2009;57(6):654-63.

39. Peer-reviewed Publications Page. Citations listing this current manuscript and appendices provided to supplement this manuscript. The National Dental Practice-Based Research Network. Development of a Patient-Based Provider Intervention for Early Caries Management. http://nationaldentalpbrn.org/studyresults/development-of-a-patient-based-providerintervention-for-early-cariesmanagement.php. Accessed 22 Mar 2017; Study Questionnaire for Dentist Survey. http://www.nationaldentalpbrn.org/tyfoon/site/fckeditor/F\%2032\%20 Dentist\%20questionnaire\%20clean\%20copy\%20052008\%20_4_.pdf. Assessed 29 Sept 2016; Study Questionnaire for Patient Telephone Survey. http://www. nationaldentalpbrn.org/tyfoon/site/fckeditor/F\%2032\%20Patient\%20telephone \%20survey\%20092608\%20clean\%20copy\%20_2_.pdf. Assessed 29 Sept 2016; Patient Education Brochure. http://www.nationaldentalpbrn.org/tyfoon/site/ fckeditor/NIT\%20Patient\%20education\%20brochure\%20061509\%20FINAL.pdf. Assessed 29 Sept 2016; Practitioner Individual Training Session. http://www. nationaldentalpbrn.org/tyfoon/site/fckeditor/F32\%20Practitioner\%20 presentation\%20FINAL.pdf. Assessed 29 Sept 2016; Study 10: Development of a patient-based provider intervention for early caries (Patient Survey). http://nationaldentalpbrn.org/tyfoon/site/fckeditor/F32_Study_Patient_Survey_ 012610.pdf. Assessed 29 Sept 2016; Dental PBRN Study 10: Caries Risk Assessment Form (Ages>18). http://nationaldentalpbrn.org/tyfoon/site/fckeditor/ Caries\%20Risk\%20Assessment\%20Form.pdf. Assessed 29 Sept 2016; DPBRN Study 10-phase 2: Consecutive Patient Log. http://nationaldentalpbrn.org/tyfoon/site/ fckeditor/Consecutive\%20patient\%20log\%20Study\%2010\%20Faculty\%20practice \%20012009\%20clean\%20copy.pdf. Assessed 29 Sept 2016; Dental PBRN Study 10: Development of a Patient-Based Provider Intervention for Early Caries. http:// nationaldentalpbrn.org/tyfoon/site/fckeditor/Study\%20F32\%20Data\%20Collection \%20Form\%20111209\%20clean\%20copy.pdf. Accessed 29 Sept 2016.

40. Bruera E, Sweeney C, Calder K, Palmer L, Benisch-Tolley S. Patient preferences versus physician perceptions of treatment decisions in cancer care. J Clin Oncol. 2001;19(11):2883-5.

41. Coulter A, Peto V, Doll H. Patients' preferences and general practitioners' decisions in the treatment of menstrual disorders. Fam Pract. 1994;11(1):67-74.

42. Gerbert B, Bleecker T, Saub E. Dentists and the patients who love them: professional and patient views of dentistry. J Am Dent Assoc. 1994;125(3):264-72.

43. Corah NL. Dental anxiety: assessment, reduction and increasing patient satisfaction. Dent Clin North Am. 1988;32(4):779-90.

44. Chakraborty G, Gaeth GJ, Cunningham M. Understanding consumers' preferences for dental services. J Health Care Mark. 1993;13(3):48-58.

45. Mellor AC, Milgrom P. Dentists' attitudes toward frustrating patient visits: relationship to satisfaction and malpractice complaints. Community Dent Oral Epidemiol. 1995;23(1):15-9.
46. Ståhlnacke K, Söderfeldt B, Unell L, Halling A, Axtelius B. Patient satisfaction with dental care in one Swedish age cohort. Part 1: descriptions and dimensions. Swed Dent J. 2007;31(2):103-11.

47. Garfunkel E. The consumer speaks: How patients select and how much they know about dental health care personnel. J Prosthet Dent. 1980;43(4):380-4.

48. Corah NL, O'Shea RM, Pace LF, Seyrek SK. Development of a patient measure of satisfaction with the dentist: the Dental Visit Satisfaction Scale. J Behav Med. 1984;7(4):367-73

\section{Submit your next manuscript to BioMed Central and we will help you at every step:}

- We accept pre-submission inquiries

- Our selector tool helps you to find the most relevant journal

- We provide round the clock customer support

- Convenient online submission

- Thorough peer review

- Inclusion in PubMed and all major indexing services

- Maximum visibility for your research

Submit your manuscript at www.biomedcentral.com/submit
C Biomed Central 